\title{
Education in Science - A Viewpoint from Jamaica
}

\begin{abstract}
In the following guest editorial based on a recent contribution in the newsletter of the Geological Society of Jamaica, Hu Gentles expresses clearly and succinctly a situation common to many countries - the need for a better appreciation of the potential of science for transforming societies. Similar concerns have recently been expressed by the IUGS Commission on Geology Teaching which is working to develop a program of activities to increase "geological literacy" world-wide.
\end{abstract}

In science lies the best opportunity for a poor country such as Jamaica to increase its limited resources and to enlarge the options for its people. Science not only satisfies intellectual curiosity but, in helping us to understand how the physical world works, enables us to apply the principles so as to reorder the physical environment for human convenience - to prevent and cure disease, to improve shelter and nutrition, to design better tools, to communicate more efficiently and to produce goods beyond the needs of mere subsistence.

In the United States, Japan or West Germany, the preceding paragraph would hardly be written in the year 1983, so obvious and widely accepted is the point. In Jamaica however, we still live in a pre-scientific culture while hankering for the products of a scientific world. Here we believe in the primacy of political solutions and in sport, tealeaf reading, revival table and gospel healing tent, "do-goodman", horoscope and other anodynes. We have no firm understanding of the relationship between our technical incapacity and the chronic unemployment and low standard of living of the vast majority of our people.

A society which watches untroubled while its already inadequate capacity to produce geologists, physicists, chemists, biologists, engineers and technicians is steadily eroded is not about to solve its problems. And the scientific community, in so far as it permits this erosion to continue, is failing in its responsibilities as a part of the society's elite. Scientists cannot content themselves with doing their jobs and leaving politicians and the rest to their "frivolities".

Without a sharp improvement in the quality of science education, we are reducing our future capacity to produce precisely those things that we all agree are needed most: energy, water, production on farm and in factory, jobs, foreign exchange. A trained and diligent intelligence is more valuable than minerals in the ground, as the Japanese demonstrate well.

In Jamaica it is a matter of particular concern that the number of qualified teachers of science is now down to a virtual handful. The number never was high in relation to the need, but a qualified teacher of physics, for example, is now a rare if not extinct creature in our schools, and the trend is similar in other scientific disciplines. What is most alarming is that society does not appear to be worried by the situation.

Shortage of resources cannot be the only reason for this deficiency in the education of our young. The business community is far readier to support beauty contests, horse racing and sports than education. Schools themselves appear to be more concerned with football trophies than with English grammar, much less science laboratories. The question is one of priorities: where shall we put such resources as we have, in what amounts and with what expectation of pay-back on the social investment? This is not only a matter for governments; it concerns the entire society.
Among other things, improvement implies better salaries and facilities so as to recruit and hold qualified science teachers. All teachers it is true, deserve a better deal, but we must not shrink from the idea of a pay differential for qualified science teachers or from recruitment abroad - two ideas which are resisted by the teachers' organizations in which, needless to say, science teachers are few. The quality of science education thus involves political decisions and is far too important to be left solely to politicians who are soon trapped by the clamorous urgencies of the short run. This means that members of the small scientific community in Jamaica must make their voices heard - with clarity, with determination, and with patience too - about the place of science in this country. The case is urgent!

Hu Gentles Kingston, Jamaica

\section{ANNOUNCEMENT}

We are pleased to announce that, beginning with this issue, EPISODES is being distributed on a complimentary basis to some 150 geoscience organizations which are unable to subscribe because of currency problems. This arrangement, which will continue for one year, has been made possible by funds from Unesco aimed at increasing the international flow of scientific information especially to developing countries.

The separate arrangement, by which a regular subscriber can purchase a second gift subscription at $\$ 10$ (US) for a recipient in a developing country, will also continue. This represents a practical, concrete and inexpensive way for individual scientists in industrialized countries to contribute to a more equitable exchange of information. A subscription form can be found elsewhere in this issue.

\section{FORTHCOMING TITLES}

Geology of the Brazilian Continental Margin

Evolution of the Guiana Shield

Red Sea Ore Deposits

Comparative Subductology

New Aproaches to Mapping Granites

Developing Small Mines and Mineral Industries 